\title{
PERAN SUAMI TERHADAP PEMILIHAN KONTRASEPSI IUD DI PRAKTEK MANDIRI BIDAN KABUPATEN SLEMAN
}

\author{
Istri Utami \\ Program Studi Kebidanan Program Sarjana Terapan \\ Fakultas Kesehatan Universitas 'Aisyiyah Yogyakarta \\ istriutami@unisayogya.ac.id
}

\begin{abstract}
Abstrak
Latar Belakang :Menurut World Population (2015) Indonesia merupakan negara populasi besar ke-5 di dunia dan terbesar di antara 9 negara ASEAN dengan jumlah penduduk 255 juta dan memiliki total fertility rate (TFR) 2,6 dengan rata-rata TFR di ASEAN 2,4. Prevalansi pemakaian alat kontrasepsi atau Contraceptive Prevalance Rate (CPR) di Indonesia menunjukkan tingkat kesertaan ber KB pasangan usia subur (PUS) mencapai 61,9. Penggunaan kontrasepsi didominasi oleh penggunaan alat kontrasepsi jangka pendek, terutama suntikan mencapai $31,9 \%$ sedangkan tingkat pemakaian metode $\mathrm{KB}$ jangka panjang hanya sebesar 10,6\% (SDKI, 2012).Berdasarkan data BKKBN, pada tahun 2014 pencapaian peserta KB aktif di Indonesia mencapai 35.202 .908 peserta. Dimana penggunaan KB suntikan sebesar 16.734.917 (47,54\%), pil sebesar 8.300.362 (23,58\%), kondom sebesar 1.110.341 (3,15\%), IUD sebesar 3.896.081 (11,07\%), implant sebesar 3.680.816 (10,46\%), MOP sebesar 241.642 $(0,69 \%)$, MOW sebesar 1.238 .749 (3,52\%). Tujuan penelitian adalah untuk mengetahui gambaran peran suami terhadap pemilihan kontrasespsi IUD Di Bidan Praktek Mandiri Kabupaten Sleman.

Metode: penelitian menggunakan deskriptif kualitatif dengan pendekatan studi Pengumpulan data dengan Indepht Interview (wawancara mendalam), analisa data kualitatif meliputi pengumpulan data, reduksi data, penyajian data, dan penarikan kesimpulan.

Hasil : Hasil penelitian menunjukan bahwa peran suami dalam pemilihan alat kontrasepsi IUD masih terkendala dengan rendahnya pengetahuan suami, sikap permisif suami dalam pemilihan kontrasepsi, kurang memanfaatkan media massa dalam mencari informasi dan perlu adanya dukungan promosi kesehatan dari tenaga kesehatan.

Kesimpulan : peran suami masih harus ditingkatkan baik dalam segi informasi untuk menambah pengetahuan, dukungan pemanfaatan media massa dan informasi dari tenaga kesehatan agar dapat berperan dalam membantu ibu memilih alat kontrasepsi yang sesuai dengan ibu
\end{abstract}

Kata kunci : peran suami, pemilihan kontrasepsi, IUD, kualitatif.

\begin{abstract}
Background: World Population (2015) declared Indonesia becoming the 5th largest population in the world and the largest population in Association of South East Asian Nation (ASEAN) with 255 million populations. Indonesia's total fertility rates (TFR) were 2.6. It was more than 2.4 as ASEAN TFR. The prevalence of contraceptive rates (CPR) in Indonesia were 61.9. This rate showed family participation in reproductive age. The short-term contraseption methods dominated to use. The highest method was injections by $31.9 \%$. On the otherhand, the longterm methods only reached $10.6 \%$ (IDHS, 2012). Data from national population and family planning agency in 2014 declared 35,202,908 participants using contraception methods. The methods were Injetions $(47.54 \%)$, pills $(23.58 \%)$, condoms $(3.15 \%)$, IUDs $(11.07 \%)$, implants $(10.46 \%)$, vasectomis $(0.69 \%)$, and tubectomis $(3.52 \%)$. The aim of this study was describing
\end{abstract}


the spouse's role of choosing IUD as mother contraception method in midwifery clinic in Sleman.

Method: the study was descriptive qualitative study by indepth interview as the data collection method.The qualitative data analysis included data collection, data reduction, data presentation, and conclusion drawing'

Results: The result of this study found many factors affecting the choosing of IUD. The factors were the lack of spouse's knowledge, the spouse's permissive attitude of contraception choosing, the lack of utilizing mass media in seeking information, and the lack of health promotion from providers to spouse.

Conclusion: Spouse's role is needed to improve the appropriate contraception method choosing. The ways to improve it were increasing spouse's knowledge, utilizing mass media, and increasing providers' role to give the information to spouses.

Keywords: Spouse's role, contraception selection, IUD, qualitative. 
Pendahuluan Indonesia merupakan negara ASEAN yang memiliki penduduk terbanyak dengan jumlah sekitar 224 juta penduduk ( World Population,2015). Total Fertility Rate (TFR) berada pada angka 2,6 sedangan rata-rata TFR di negara ASEAN pada angka 2.4. dampak dari laju pertumbuhan penduduk yaitu sebagian besar penduduk tidak mendapat layanan kesehatan yang berkualitas, sehingga pemerintah mencanangkan program Keluarga Berencana (BKKBN,2015). Survei Ekonomi Nasional memperlihatkan angka unmet need yang meningkat sekitar 4-5\% ( Susenas, 2015).

Metode kontrasepsi yang rekomendasikan BKKBN diantaranya metode kontrasepsi jangka panjang (MKJP) yaitu Intra Uterine Device(IUD) memiliki efektifitas yang tinggi (97-99\%), yaitu pemakaian IUD dengan sekali pemasangan untuk jangka waktu yang lama hingga 8 tahun (Wiknjosastro,2008). Dukungan suami merupakan salah satu variabel sosial budaya yang sangat berpengaruh terhadap pemakaian alat kontrasepsi bagi kaum wanita sebagai istri secara khusus dan didalam keluarga secara umum (Depkes, 2014). Berdasarkan uraian tersebut tujuan penelitian ini adalah untuk mengetahui peran suami terhadap pemilihan kontrasepsi IUD di Praktik Bidan
Kabupaten Sleman. Untuk mengetahuai pengaruh konseling dengan ABPK terhadap pemilihan kontrasepsi..

Metode Penelitian ini menggunakan metode deskriptif kualitatif dengan pendekatan studi kasus dilaksanakan di Praktik Mandiri Bidan di Kabupaten Sleman tahun 2017. Informan penelitian ini adalah ibu (informan utama) dan suami (informan pendukung). Informan diambil dengan metode purposive sampling di PMB Kabupaten sleman berjumlah 9 informan berasal dari ranting barat, ranting timur dan ranting tengah masing-masing diambil 3 orang yang sesuai dnegan kriteria peneliti. Penentuan pengambilan informan adalah semua ibu yang menggunakan IUD di PMB Kabupaten sleman.Pengambilan data menggunakan wawancara mendalam (indepth interview) dan catatan lapangan. Analisis data menggunakan langkah pengumpulan data, reduksi data, penyajian data dan penarikan kesimpulan (Miles and Huberman, 1992).

Hasil Praktek Mandiri Bidan adalah salah satu fasilitas kesehatan yang dilakukan oeleh bidan secara mandiri yang berada di wilayah Kabupaten Sleman.

Penggunaan kontrasepsi IUD di kabupaten Sleman mengalami penuruanan dibanding penggunan alat kontrasepsi lainnya. Praktek 
Mandiri Bidan sudah berupaya memberikan konseling dan edukasi jenis - jenis kontrasepsi kepada pasien sebelum melakukan pelayanan. Di dalam konseling ini Bidan melibatakan peran suami dalam pemilihan kontrasepsi istrinya. Baik saat pelaksanaan konseling dan pengambilan keputusan

Tabel 1. Karakteristk informan

Tabel 2. Informan triangulasi (ibu yang menggunakan IUD)

\begin{tabular}{|c|c|c|c|c|c|c|c|}
\hline \multirow{2}{*}{$\begin{array}{l}\text { Karak- } \\
\text { teristik }\end{array}$} & \multicolumn{6}{|c|}{ Informan triangulasi (Ik) } & \multirow{2}{*}{$\mathbf{J m l}$} \\
\hline & IA & IB & IC & ID & IE & IF & \\
\hline $\begin{array}{l}\text { Pendidik } \\
\text { an } \\
\text { Tamat }\end{array}$ & & & & & & & \\
\hline $\begin{array}{l}\text { SMP } \\
\text { Tamat }\end{array}$ & V & V & - & - & $\mathbf{V}$ & V & 3 \\
\hline $\begin{array}{l}\text { SMU } \\
\text { Pekerjaa }\end{array}$ & - & - & - & - & - & - & 3 \\
\hline $\begin{array}{l}\text { n } \\
\text { Buruh }\end{array}$ & - & - & - & - & - & $\mathbf{V}$ & 1 \\
\hline Swasta & $\mathbf{V}$ & - & V & - & - & - & 2 \\
\hline $\begin{array}{c}\text { wiraswas } \\
\text { ta }\end{array}$ & - & - & - & $\mathbf{V}$ & - & - & 1 \\
\hline IRT & - & V & - & - & - & - & 1 \\
\hline $\begin{array}{l}\text { Usia saat } \\
\text { ini }\end{array}$ & & & & & & & \\
\hline $\begin{array}{l}<35 \text { th } \\
>35 \text { th }\end{array}$ & $\begin{array}{l}\mathbf{V} \\
-\end{array}$ & $\begin{array}{l}V \\
-\end{array}$ & v & - & $\overline{\mathbf{V}}$ & $\overline{\mathbf{V}}$ & $\begin{array}{l}2 \\
3\end{array}$ \\
\hline
\end{tabular}

Pembahasan. Hasil wawancara mendalam (Indepth interview)

\section{Pengetahuan tentang kontrasepsi IUD}

Pengetahuan Informan kontrasepsi IUD sebagian besar (enam Informan) belum tahu, seperti diungkapkan oleh Informan, sebagai berikut:

“...alat spiral yang di masukan dalam perut " $(I-A)$ “...saya tidak tahu...manut aja dengan pilihan isteri...” (I-D)

“ .....istri saya sudah tidak pingin hamil lagi, makanya pake KB Spiral...” ( I -B)

Sementara ada satu Informan yang dapat menjelaskan proses pemasangan IUD seperti yang diungkapkan sebagai berikut:

“...pemasangan spiral pasien diminta

\begin{tabular}{|c|c|c|c|c|c|c|c|}
\hline \multirow{2}{*}{$\begin{array}{l}\text { Karak- } \\
\text { teristik }\end{array}$} & \multicolumn{6}{|c|}{ Informan (I) } & \multirow{2}{*}{$\mathbf{J m l}$} \\
\hline & I-A & I-B & I-C & I-D & I-E & I-F & \\
\hline $\begin{array}{l}\text { Pendidik } \\
\text { an } \\
\text { Tamat }\end{array}$ & & & & & & & \\
\hline $\begin{array}{l}\text { SMP } \\
\text { Tamat }\end{array}$ & $\mathbf{V}$ & - & - & V & $\mathbf{V}$ & - & 3 \\
\hline $\begin{array}{l}\text { SMU } \\
\text { Usia saat }\end{array}$ & - & V & $\mathbf{V}$ & - & - & $\mathbf{V}$ & 3 \\
\hline $\begin{array}{l}\text { ini } \\
>30\end{array}$ & & & & & & & \\
\hline tahun & - & - & $\mathbf{V}$ & - & - & - & 6 \\
\hline
\end{tabular}
pemasangan IUD dimasukan dalam rahim dengan alat khusus..." (I-B)

Sedangkan pengetahuan tentang bagaimana efektifitas dari KB IUD semua informan memiliki pemahaman yang sama bahawa IUD bisa mencegah kehamilan,seperti yang diekmukakan sebagai berikut :

“..spiral dapat mencegah kehamilan, karna dulu pernah menggunakan KB yang sama dan tidak ada keluhan makanya ini pingin make KB lagi sudah nggak mau nambah anak lagi....(I-E)

“...tapi katanya klo make KB spiral buat hubungan sakit aya buu..." (I-C)

“....iya kadang saat hubungan suami istri memang terasa nyekrik ada apa gituu вии..." (I-F) 
Sedangkan efek samping yang di timbulkan

KB IUD semua Informan mengetahui bahwa dapat berakibat mengakibatkan menstruasi yang lama dan banyak seperti yang diungkapkan Informan sebagai berikut:

“...ya setelah menggunakan KB IUD ini istri saya klo menstruasi jadi banyak banget dan kadang mengeluh nyeri ..." (IF)

“...saya ngrasain..dikucilkan dan temanteman podo njauhin.." (I-A)

Ada satu informan yang mengatakan lebih aman mengunakan kondom, seperti yang diungkapkan sebagai berikut:

“..lebih enak klo pake ..(kondom)...pake kondom tidak menyebabkan apapun .." (IC)

Berdasar pernyataan di atas dapat dijelaskan bahwa pengetahuan para informan tentang penggunaan KB IUD kurang baik. Penelitian ini sesuai dengan penelitian yang dilakukan oleh Solihati (2008) bahwa salah satu faktor yang berhubungan dukungan pemilihan kontrasepsi di kalangan suami adalah tingkat pengetahuan yang rendah tentang pengetahuan kontrasepsi IUD Kusmiran (2011). Hasil penelitian ini sejalan dengan Al-qur'an surat Az-Zumar ayat 9 yang artinya:

“........Katakanlah: "Adakah sama orang-orang yang mengetahui dengan orang-orang yang tidak mengetahui?" Sesungguhnya orang yang berakallah yang dapat menerima pelajaran" (Q.S.

Az-Zumar : 9)

Orang yang mempunyai pengetahuan lebih memiliki kesadaran untuk melakukan sesuatu berdasarkan keyakinan dibandingkan dengan orang yang tidak memiliki pengetahuan, yang lebih hanya meniru-niru perbuatan orang lain. House (1990) dalam Morton (1995) bahwa pengetahuan (knowledge)adalah kemampuan intelektual yang berhubungan dengan fakta, kebenaran atau pengembangan prinsip dengan cara melihat dan merasakan. Sedangkan Azwar (2007) mengemukakan bahwa pengetahuan merupakan domain yang sangat penting untuk menimbulkan sikap dan perilaku seseorang.

Jika dilihat tingkat pendidikan Informan lulusan SMP dan SMU termasuk kategori cukup yang sebenarnya lebih banyak menerima informasi KB IUD dari teman dan media sehingga informasi yang diterima dapat mempengaruhi dukungan suami terhadap pemilihan kontrasepsi IUD. Namun ternyata pengetahuan mereka tergolong rendah. Oleh karena itu, kurangnya pengetahuan responden tentang kontrasepsi IUD merupakan salah satu faktor yang mempengaruhi dukungan suami terhadap pemilihan kontrasepsi.

Berdasarkan hasil wawancara terkait dukungan suami terhadap pemilihan kontasepsi sebagai berikut : 
Gambar 3. Pengetahuan tentang

\section{kontrasepsi}

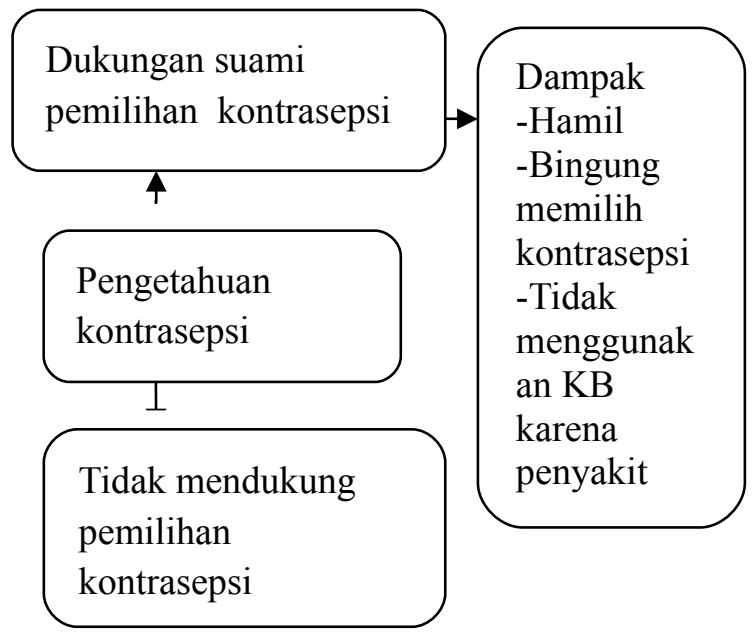

2. Sikap terhadap pemilihan kontrasepsi

Sikap terhadap dukungan pemilihan kontrasepsi KTD digali terkait dengan tanggapan Informan mengenai dukungan suami sebagai berikut:

“...saya hanya manut sama pilihan istri saya, saya tidak tahu macam - macam alat kontasepsi..." (I-A)

Pada saat ditanyakan apakah pertama kali ini menggunakan kontrasepsi IUD, empat Informan mengatakan tidak, karena sebelumnya sudah pernah menggunakan kontrasepsi yang sama. seperti yang dikemukakan oleh salah satu informan, sebagai berikut:

“...... saya baru mengijinkan istri saya menggunakan KB IUD yang katamya nggak perlu kontrol terus dan bisa di pake waktu yang sangat lama...." (I-A)

“......Sebenarnya menggunakan KB IUD itu lebih enak adri pada suntik yang hrus tiap bulan mengantar istri saya datang ke sini....." $(I-A)$

3. Akses Media Informasi tentang Kontrasepsi

Akses media masa dikaji tenatng frekuensi akses dan pengaruhnya. Dari hasil wawancara diperoleh hasil semua Informen pernah mengakses informasi tentang macam macam alat kontrasepsi baik secara sendiri maupun dengan bersama istrinya untuk menentukan pilihan kontrasepsinya. , seperti yang dikemukakan sebagai berikut : “....saya sering mengakses informasi jenis jenis kontrasepsi lewat goegle ..." (I-F)

Ada juga Informan mengakses informasi sendiri seperti diungkapkan sebagai berikut:

“. lah istri saya bingung mau menggunakan kontasepsi apa, saya pingin tahu aja apa sih jeneis jenis alat KB itu k...."(I-C)

Pada masa teknologi yang berkembang pesat saat ini maka sangat memungkinkan para suami dapat mengakses berbagai informasi dengan benar. Para Informan memiliki sarana gadged untuk mengakses berbagai informasi termasuk akses informasi yang lainya.Sikap informan terhadap dukungan pemilihan kontrasepsi, Mereka memberikan tanggapan bahwa memeberikan dukungan pemilihan kontasepsi sangat penting jangan sampai istri salah menggunakan kontrasepsi. 
Penelitian Nawirah 2015 mengatakan bahawa salah satu faktor yang mempengaruhi pemilihan kontrasepsi adalah dukungan suami.Berdasarkan hasil penelitian dapat diketahui bahwa semua Informan belum mengetahui tentang informasi macam macam alat ontrasepsi dengan lengkap, mereka ghanya mendudkung dengan pilihan istrinya untuk menggunakan KB IUD.

Kesimpulan. Hasil penelitian menyebutkan bahwa peran suami terhadap dukungan pemilihan kontrasepsi IUD yaitu masih rendahnya pengetahuan jenis kontrasepsi, sikap permisif dalam memberikan dukungan pemilihan kontrasepsi, pengaruh media masa dan kurangnya informasi jenis-jenis alat kontrasepsi dan cara kerja kontrasepsi tersebut dari tenaga kesehatan. sehingga diharapkan bagi suami dapat menvari sumber informasi yang tepat sehingga dapt memberikan dukungan yang sesuai dan didukung oleh tenaga kesehatan untuk meningkatkan upaya promosi kesehatan kepada PUS terkait jenis kontrasepsi secara lengkap serta memberikan konseling kepada pasangan (suami dan ibu) agar dapat menentukan kontrasepsi secara bersama.

\section{Daftar pustaka}

Alistiyowati, D. 2007. Hubungan Dukungan Sosial Suami dengan Depresi Pasca Persalinan Pada Perempuan Primipara. Universitas Katolik Soegijapranata. Semarang.

Ariani, E. 2012. Faktor-faktor yang Mempengaruhi Pemilihan Alat Kontrasepsi di Puskesmas Pleret Bantul. Skripsi Stikes 'Aisyiyah Yogyakarta.

Azwar, M.A. 2015. Sikap Manusia Teori dan Pengukurannya. Pustaka Pelajar.Yogyakarta.

Badan Pusat Statistik \& Macro Internasional. 2008. Survei Demografi dan Kesehatan Indonesia Tahun 2007, Calverton, Maryland, Macro Internasional. USA

Bernadus D. J, Madianung A dan Masi G. 2013. Faktor-faktor yang Berhubungan dengan Pemilihan Alat Kontrasepsi Dalam Rahim (AKDR) Bagi Akseptor KB Di Puskesmas Jailolo. Jurnal eNERS (eNs). Vol 1. No 1. Maret 2013. Hal 1-10.

BKKBN. 2010. Program Keluarga Berencana dan Kemiskinan. Yogyakarta

- 2014. Kesertaan Keluarga Berencana dan Faktor-faktor yang Berhubungan dengan Terjadinya Unmet Need KB pada Pasangan Usia Subur di Kota Yogyakarta. Jakarta: Pusat Penelitian dan Pengembangan Kependudukan. . 2014. Petunjuk Pelaksanaan Program K $B$. BKKBN. Jakarta. 
2015. Pusat Data dan Informasi Kementerian Kesehatan RI. Yogyakarta.

Bobak, Lowdermik \& Jensen. 2005. Buku Ajar Keperawatan Maternitas Edisi 4EGC. Jakarta

BPS. Survei Demografi dan Kesehatan Indonesia. 2012. Jakarta.

Departemen Agama RI. 2007. Al Qur'an dan Terjemahan. Alfa Beta. Jakarta.

Depkes. 2015. Situasi Keluarga Berencana Indonesia. Jakarta Vol. 2.

.(2014).

Http://Www.Academia.Edu/533 1634/Keputusan Menteri

Kesehatan Republik Indonesia Nomor 369 Menkes SK II 2007 Diakses pada tanggal 23 Desember 2016.

Handayani, S. 2012. Keluarga Berencana dan Kontrasepsi. Pustaka Rihana. Yogyakarta

Komang, A. 2014. Hubungan Persepsi Ibu tentang Dukungan Suami Terhadap Tingkat Keberhasilan IMD di Rumah Sakit. Universitas Gadjah Mada. Yogyakarta.

Kusumaningrum, R. 2009. Faktor-faktor yang Mempengaruhi Pemilihan Jenis Kontrasepsi yang Digunakan pada Pasangan Usia Subur. UNDIP. Semarang.

Manuaba. 2009. Ilmu Kebidanan, Kandungan, dan KB. EGC. Jakarta
Maryatun. 2009. Analisis Faktor-faktor Pada Ibu yang Berpengaruh Terhadap Pemakaian Metode Kontrasepsi IUD di Kabupaten Sukoharjo Gaster. Stikes Aisyiyah Surakarta.

Moleong, LJ. 2014. Metodologi Penelitian Kualitatif Edisi Revisi. Remaja Rosdakarya. Bandung.

Nawirah. 2015. Faktor-faktor yang Mempengaruhi Pemilihan Kontrasepsi IUD di Wilayah Kerja Puskesmas Wonomulya. Universitas Hasanudin. Makassar.

Pertiwi. 2013. Hubungan usia, paritas, dan Dukungan Suami dengan Pemilihan Kontrasepsi IUD di Dusun Getasan Kabupaten Semarang. Diakses pada tanggal 12 Januari 2017.

Peter McDonald, Ria Rahayu. 2009. Contraceptive Use Pattern Among Married Women In Indonesia. International Conference on Family Planning Research and Best Pratices. Kampala Uganda.

Pinem, 2009. Kesehatan Reproduksi dan Kontrasepsi. TIM. Jakarta.

Sarwono. 2009. Ilmu Kebidanan. Yayasan Bina Pustaka. Jakarta.

Shattuck, D., Kerner, B., Gilles, K., Hartmann, M., Ng'ombe, T., Guest, G. 2011. Encouraging Contraceptive Uptake by Motivating Men to Communicate About Family Planning : The Malawi Motivator Project. Vol.101, No.6. 
Suratun S., Sri M. 2008. Pelayanan Keluarga Berencana dan Pelayanan Kontrasepsi. Jakarta: Natawijaya.

Susiana, S. 2015. Faktor yang Berhubungan dengan Terjadinya Unmet Need KB pada Pasangan Usia Subur di Kota Yogyakarta. Stikes Alma Ata Yogyakarta. Vol.3.

Wiknjosastro, H. 2009. Ilmu Kebidanan. Yayasan Bina Pustaka Sarwono Prawirohardjo. Jakarta.

WHO/RHR \& Center For Communication Programs. 2007. Family Planning: A Global Handbook for Providers, Baltimore and Geneva: CCP and WHO.
WHO. 2007. Ragam metode kontrasepsi.. EGC. Jakarta.

Yanikkerem, E. 2006. Withdrawal Users' Perceptions of and Experience With Contraceptive Methods In Manisa, Turkey. Midwifery Volume 22. 274-284.

Zaheen, Baig. 2012. Factor Affecting Hormonal and Non Hormonal Contraceptive Method Use In Women Presenting to Reproductive Health Services-A Centers (RHS-A) of Karachi. IOSR Journal of Dental and Medical Sciences (JDMS) Volume 2, Issue 1 (Sep-Oct. 2012). Bahria University Medical \& Dental Collage Department Of Community Health Sciences. 
